\title{
The influence of polymorbidity, revascularization, and wound therapy on the healing of arterial ulceration
}

\author{
Joerg Tautenhahn' \\ Ralf Lobmann ${ }^{2}$ \\ Brigitte Koenig ${ }^{3}$ \\ Zuhir Halloul' \\ Hans Lippert' \\ Thomas Buerger' \\ 'Department of General, Visceral \\ and Vascular Surgery; ${ }^{2}$ Department \\ of Endocrinology and Metabolism; \\ ${ }^{3}$ Institute for Medical Microbiology, \\ Medical School, Otto-von-Guericke \\ University, Magdeburg, Germany
}

\begin{abstract}
Objective: An ulcer categorized as Fontaine's stage IV represents a chronic wound, risk factor of arteriosclerosis, and co-morbidities which disturb wound healing. Our objective was to analyze wound healing and to assess potential factors affecting the healing process.

Methods: 199 patients were included in this 5-year study. The significance levels were determined by chi-squared and log-rank tests. The calculation of patency rate followed the Kaplan-Meier method.

Results: Mean age and co-morbidities did not differ from those in current epidemiological studies. Of the patients with ulcer latency of more than 13 weeks (up to one year), $40 \%$ required vascular surgery. Vascular surgery was not possible for 53 patients and they were treated conservatively. The amputation rate in the conservatively treated group was $37 \%$, whereas in the revascularizated group it was only $16 \%$. Ulcers in patients with revascularization healed in $92 \%$ of cases after 24 weeks. In contrast, we found a healing rate of only $40 \%$ in the conservatively treated group $(\mathrm{p}<0.001)$. Revascularization appeared more often in diabetic patients $(\mathrm{n}=110$; $p<0.01)$ and the wound size and number of infections were elevated $(p=0.03)$. Among those treated conservatively, wound healing was decelerated $\left(\mathrm{p}=0.01 / 0.02 ; \chi^{2}\right.$ test).

Conclusions: The success of revascularization, presence of diabetes mellitus, and wound treatment proved to be prognostic factors for wound healing in arterial ulcers.

Keywords: arterial leg ulcer, wound management, risk factors, revascularization
\end{abstract}

\section{Introduction}

The underlying cause of arterial ulceration is arteriosclerosis obliterans resulting in tissue ischemia in $90 \%$ of cases. The ulcer itself is categorized as stage IV in the Fontaine classification system (Rutherford category 3 and 4). Only a few articles discuss the complex treatment of these wounds or show the influence of revascularization, wound management, and risk factor assessment. This study aimed to evaluate the factors involved in complex wound treatment.

\section{Subjects and methods}

\section{Patients}

Over a 5-year period (1997-2001), 199 patients with stage IV peripheral arterial occlusive disease (PAOD) were studied. Inclusion criteria were length of hospital stay, course of therapy, outpatient monitoring, and wound assessment/treatment (inpatient and outpatient). Risk factors, co-morbidities, and the different treatment groups were also evaluated (Figure 1). 


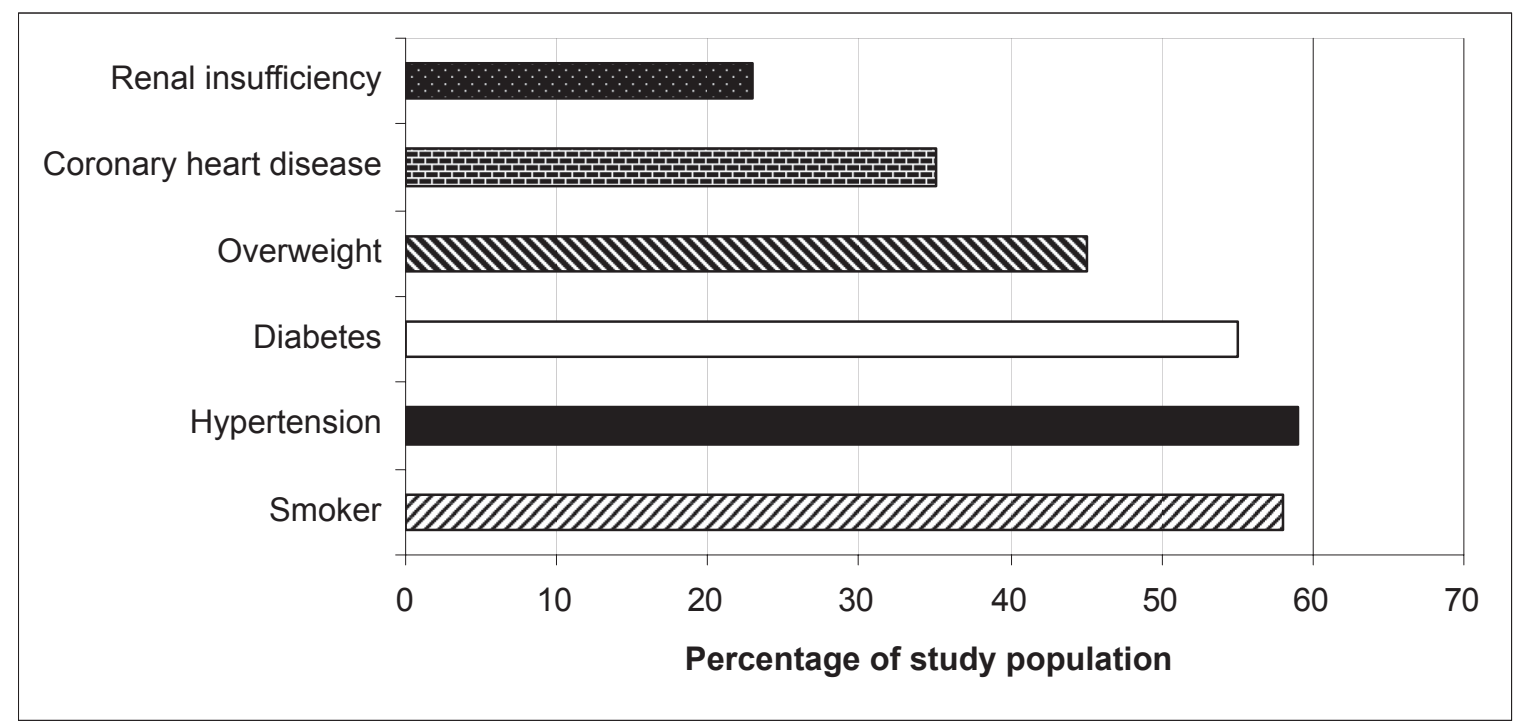

Figure I Risk factors and comorbidities.

\section{Vascular status/vascular surgery therapy} Imaging procedures such as angiography or magnetic resonance angiography (in cases with renal insufficiency or contrast agent allergy) were used to ascertain an objective status of the vascular system. The decision to perform angioplasty/reconstruction was based on the Trans-Atlantic Inter-Society Consensus guidelines (Trans Atlantic InterSociety Consensus I 2000).

\section{Wound assessment}

To characterize the wound we assessed data on latency, localization, size, and type of wound. Localization fell into three categories: foot and toe, lower leg, foot and lower leg. A lattice grid was used to measure the wound size. A wound with a spread of less than $5 \mathrm{~cm}^{2}$, or with a single extension radiating from the wound, was classified as a "small wound". A "medium-size wound" was $5-10 \mathrm{~cm}^{2}$, or with $2-4$ toes involved. The category of "large wound" included those with a spread beyond $10 \mathrm{~cm}^{2}$, and those with the involvement of the entire forefoot. The depth was categorized using the Knighton classification (Knighton et al 1986). Ulceration was defined as tissue damage which could clinically be described as necrosis or gangrene.

The diagnosis of neuropathy resulted from the known factors (Morbach et al 2004; Lobmann 2005).

\section{Wound treatment}

Wounds were treated according to Vollmar's IRA principle (treatment of infection, revascularization and minor amputation in the necrobiotic wound margin; Vollmar 1996).
Necrosis (ie, of the toes) was not removed or debrided before revascularization. A gangrenous or phlegm-filled status required surgical intervention to control wound infection (eg, incision, drainage, toe amputation) with accompanying antibiotic treatment and local application of antiseptics (Kramer et al 1998; Schmidt et al 2000). The general wound treatment followed the revised TIME principles of wound bed preparation (Bendow et al 1999; Schultz et al 2003) and did not differ from current recommendations (Hopf et al 2006). Ulcer healing, and wound borderline amputation that healed well, were considered successful outcomes.

\section{Statistical analysis}

The chi-squared and log-rank tests were used to establish the statistical significance of the determinant factors. The patency rate was calculated according to the Kaplan-Meier method. All statistical tests were performed with SPSS 11.0 for Windows (Chicago, IL, USA).

\section{Results}

\section{Patient characteristics}

The average age of the 132 men (66\%) and 67 women (34\%) was 65.4 years. Thirty-two percent of the patients were younger than 60 years. Diabetic patients were significantly older than nondiabetic patients with PAOD ( $\mathrm{p}=0.03 ; \chi^{2}$ test). Nicotine abuse was found among $72 \%$ of men and among $26 \%$ of women. Using the Body Mass Index (BMI) calculation we found that 90 patients (45\%) were overweight (BMI: 25-30) or obese (BMI: $>31$ ). Arterial hypertension was seen in $77 \%$ of 
the women and $49 \%$ of the men; of these groups $84 \%$ and $60 \%$ were overweight, respectively. There were 110 patients (55\%) with diabetes mellitus. This patient group had a greater number of previous revascularization treatments on the extremities ( $p<0.01 ; \chi^{2}$ test) than nondiabetic patients. Women more often showed the risk factor combination of arterial hypertension, diabetes mellitus, and obesity ( $p=0.02 ; \chi^{2}$ test). There were 46 patients $(23 \%)$ with chronic renal insufficiency (27 needed dialysis). Of all risk factors, only diabetes mellitus showed a correlation with poor wound healing (Figure 1).

\section{Ulcer characteristics and treatment}

We found angiopathic ulcers in 89 (45\%) patients without diabetes mellitus, whereas among the diabetic patients, we found angiopathic or angiopathic-neuropathic ulcers in 110 (55\%). Diabetic patients presented significantly larger wounds ( $\mathrm{p}=0.03 ; \chi^{2}$ test) and there was a higher occurrence of phlegmonous infection ( $\mathrm{p}=0.03 ; \chi^{2}$ test). Wound localization and necrotic status or gangrene did not differ significantly between the two groups (PAOD patients with/ without diabetes mellitus) (Table 1). After ulcer duration of more than 13 weeks, $40 \%$ of the patients were presented for vascular surgery (Figure 2). Pre- and post-operative antibiotic therapy was administered to $67 \%$ of the patients because of signs of local or systemic infection (germ spectrum: 40\% Staphylococcus [3\% MRSA], 24\% Enterococcus, $20 \%$ Enterobacter, 10\% Pseudomonas, and 6\% other). Local antiseptics were applied in $58 \%$ of the cases. Sixty-seven percent of the ulcers were surgically debrided. If a patient did not have the option of revascularization, or had a small superficial ulcer, a conservative debridement was performed. During the hospitalization, $33 \%$ received modern occlusion bandaging, and in $10 \%$ a biological covering of the wound (mesh graft, $\mathrm{n}=14$; plastic flap, $\mathrm{n}=5$ ) was applied. In $37 \%$ of the cases minor amputation (toe amputation) was performed after revascularization. An inactive dressing was placed on the necrotic tissue until a necrobiotic borderline had developed.

\section{Vascular situation/treatment}

Twenty-three percent of the cases had undergone previous vascular surgery on the affected extremity $(10 \%$ on the contralateral extremity). Major amputation was required in $2 \%$ of the ipsilateral (lower leg) and $4 \%$ of the contralateral (lower leg and upper leg) cases.

Sixty-one percent of the patients had a multilevel occlusive disease; the thigh-lower leg occlusion type was predominant (Figure 3). The mean ABI (ankle/brachial index) improved by 0.37 to 0.90 (excluding $20 \%$ of the diabetic patients, who could not be analyzed). In 53 patients $(27 \%)$, the lower leg arteries were either partially or completely closed up. Whenever vascular re-connection was not possible, a conservative treatment was performed (prostaglandin infusion, acetylsalicylic acid, heparin, and pain treatment). The rate of amputation was $37 \%$ in this conservatively treated group. Vascular surgery was performed on $146(73 \%)$ of the patients. A total of 178 surgical interventions was necessary, ie, angioplasty and bypass/endarterectomy, endarterectomy and bypass, thrombolysis. Because of the relatively small number of cases, and the variation in surgical procedures and vascular status, the patency rate is not meaningful for evaluating the outcome of treatment (Leng et al 2000). A saphenous vein bypass, as opposed to a prosthetic bypass, was more advantageous in the upper as well as in the lower $\operatorname{leg}(\mathrm{p}=0.01$; log-rank test). In the revascularized group the amputation rate was only $16 \%(n=24)$.

\section{Outcome}

The average hospital stay was 22 days (range: 12-29 days). The time delay until the vascular operation was determined by the status of the infection and time needed for assessment and treatment of the polymorbidities (median: 5 days; range: 1-10 days). To assess wound treatment we monitored 150 wounds (117 patients of the revascularized group and 33 patients of the conservatively treated group). The amputated $(n=43)$ and the patients who died during their first hospital stay $(n=6)$ were not included in the analysis.

Table I Wound characterization $(\mathrm{n}=199)$

\begin{tabular}{|c|c|c|c|c|c|c|}
\hline Grading & Classification & Frequency & Size & Frequency & Location & Frequency \\
\hline I & epidermal/dermal & $7 \%$ & small $\left(<5 \mathrm{~cm}^{2}\right)$ & $37 \%$ & foot & $78 \%$ \\
\hline II & subcutaneous & $82 \%$ & $\begin{array}{l}\text { medium } \\
\left(5-10 \mathrm{~cm}^{2}\right)\end{array}$ & $35 \%$ & lower leg & $19 \%$ \\
\hline III & involving fasciae/muscles & $9 \%\left(>10 \mathrm{~cm}^{2}\right)$ & large & $28 \%$ & combination & $3 \%$ \\
\hline IV & involving tendons/bones/joints & $2 \%$ & & & & \\
\hline V & undermining cavities/fistulae & 0 & & & & \\
\hline
\end{tabular}




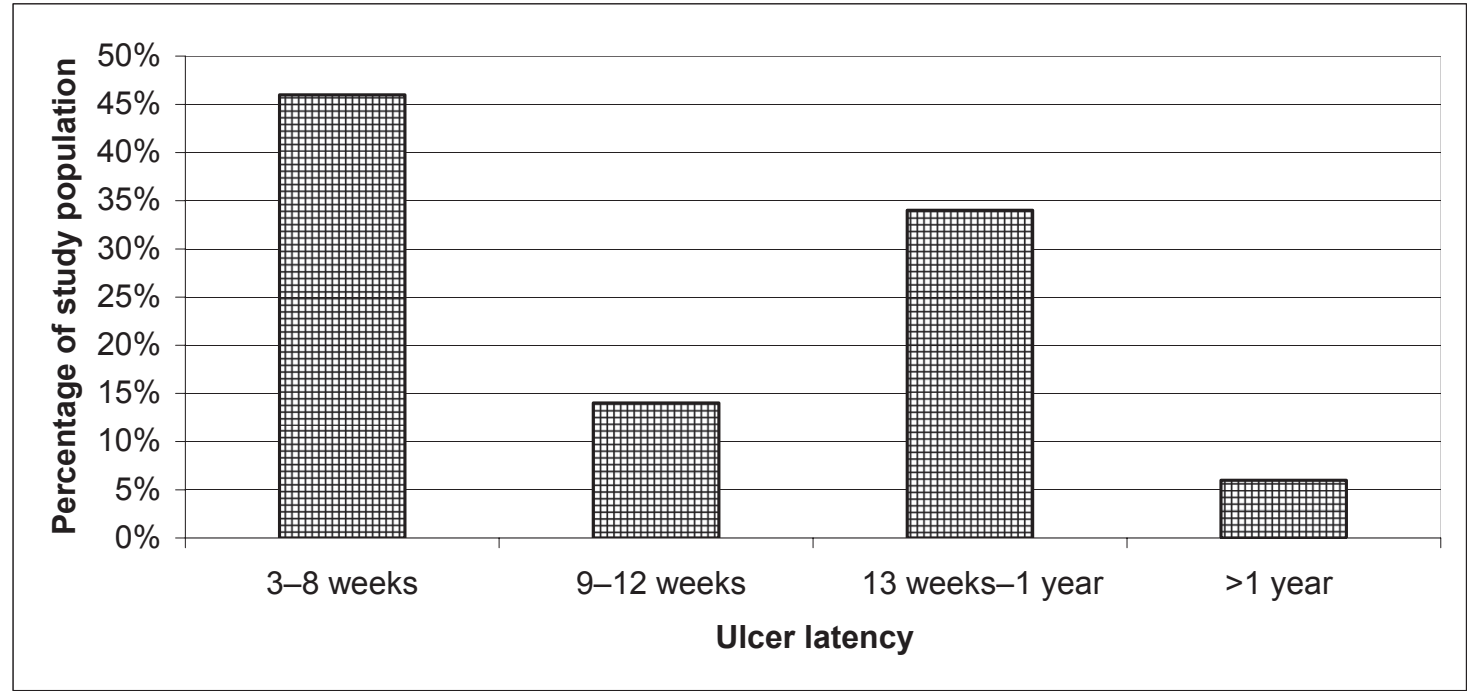

Figure 2 Ulcer latency until presentation for vascular surgery.

During our 5-year follow up, 22 patients (11\%) died. At the time of discharge, a total of $47 \%(n=70)$ of the 150 wounds had healed. Within 24 weeks, $92 \%$ of ulcers in the revascularizated group healed, whereas only $40 \%$ in the conservatively treated group showed complete wound healing at this time point (Figure 4).

Diabetic patients, and patients treated conservatively, needed an extended healing time $\left(\mathrm{p}=0.01 / 0.001 ; \chi^{2}\right.$ test). A second hospital stay was necessary for 67 patients and in
$60 \%$ the wound treatment was responsible for hospitalization (ie, borderline amputation/minor amputation, debridement). Major reasons for a third hospital stay $(\mathrm{n}=17)$ were progress of arteriosclerosis or bypass complications (Figure 5a-b). In $78 \%$ (of all patients) the leg could be preserved.

\section{Discussion}

General epidemiological data for Germany confirm that 2.5 million patients have PAOD, and 800,000 of these have

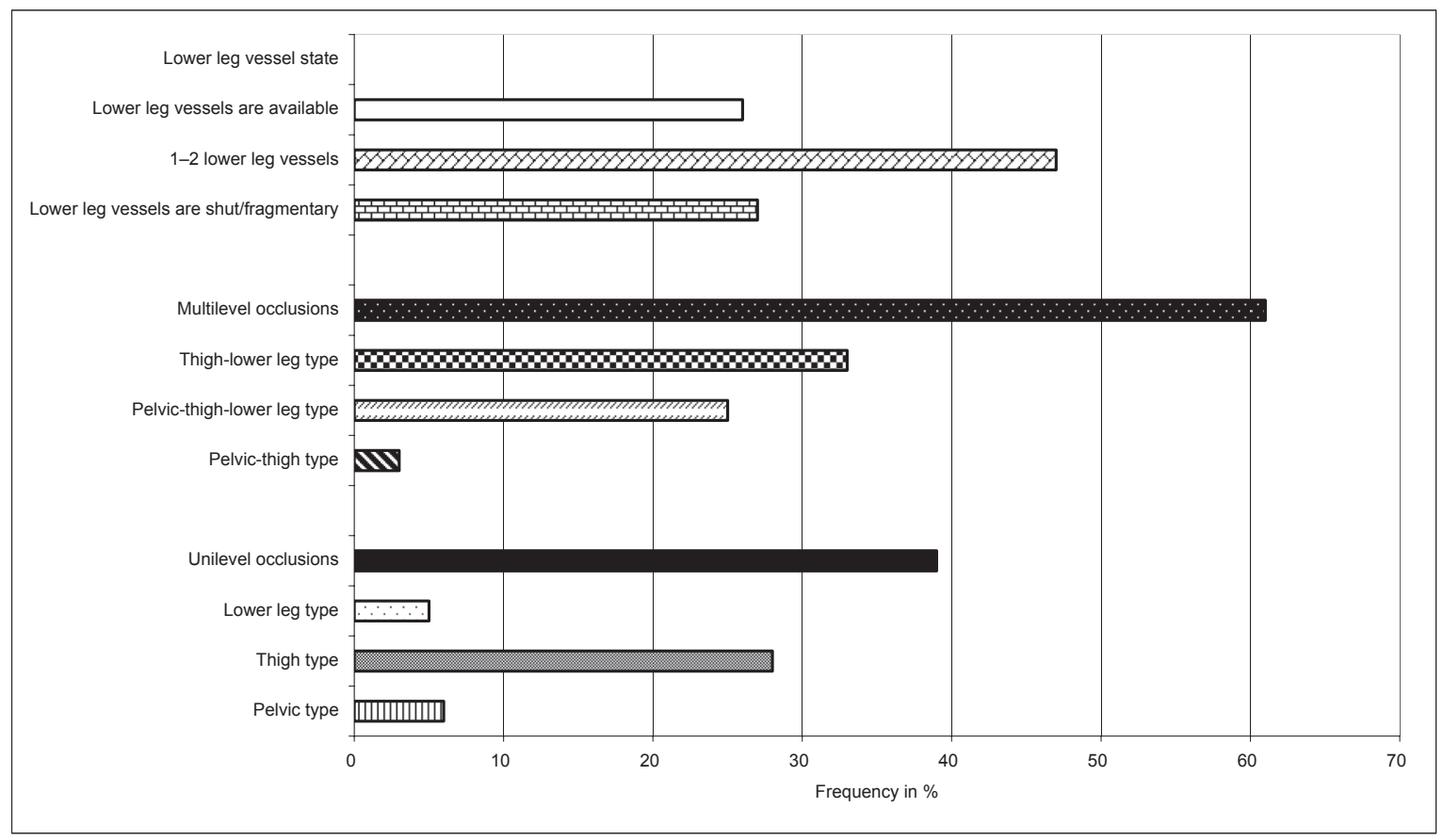

Figure 3 Vascular status of the patient with arterial ulcers. 

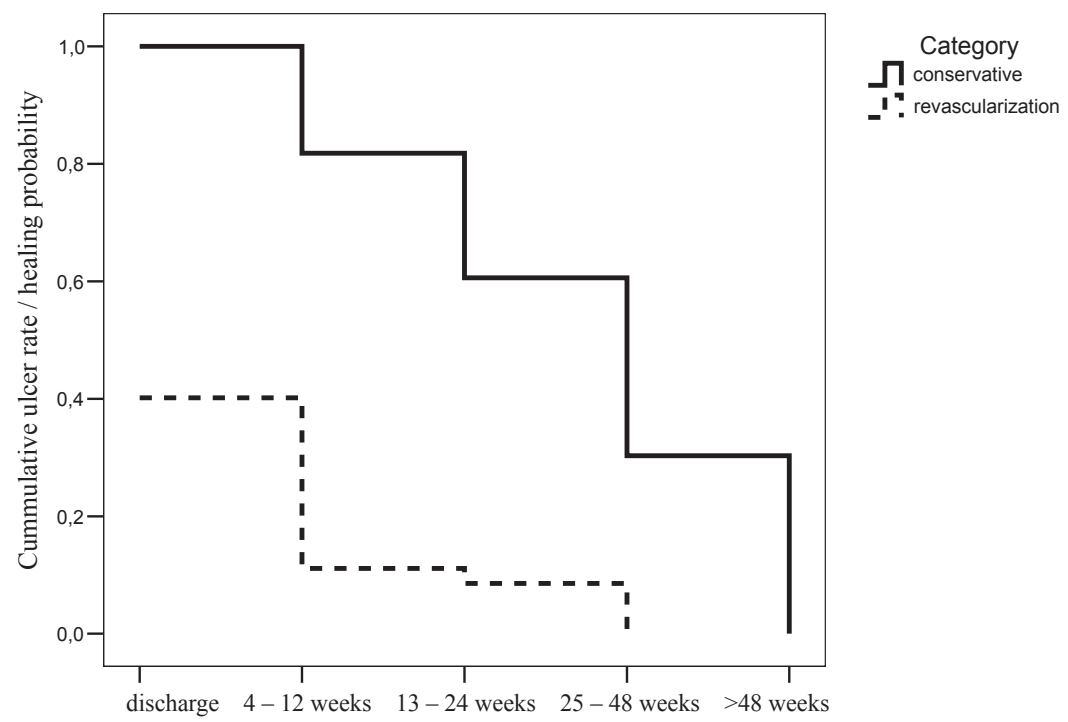

Figure 4 Rate of healing for arterial ulcers.

Notes: Conservative N 33; Vasc II7

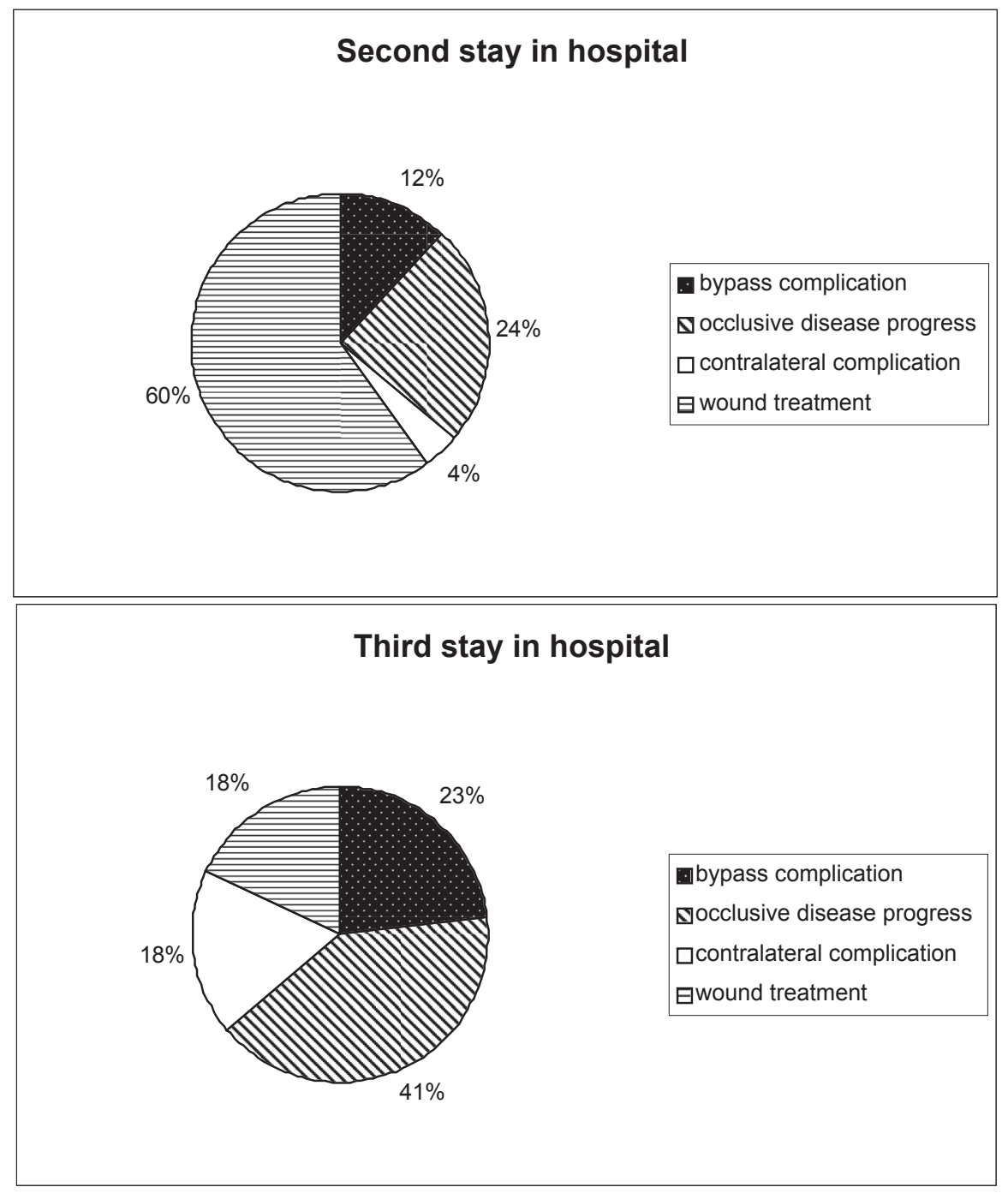

Figure 5a-b Reasons for additional hospitalization. 
clinically significant symptoms. Of the stage III and IV patients, $25 \%$ suffer a substantial disease progression during the time of treatment. The vascular component is the leading reason for 20,000 major amputations per year in Germany (Spengel 2001; getABI Study Group 2002; Cetin and Baumgartner 2004; Eckstein and Knipfer 2007).

In this study, the risk factors of PAOD are similar to those shown in published data (Treiman et al 2000; getABI Study Group 2002; Shammas 2007). In diabetic patients we found more severe infections, greater wound size, and longer healing times. The high prevalence of ischemia, infection, and serious co-morbidity in diabetic foot syndrome was confirmed in the Eurodiale study (Prompers et al 2007). The extrinsic and intrinsic factors leading to decreased healing capacity in diabetic patients were determined (Lobmann 2005). PAOD is not an independent condition in diabetic patients (Morbach et al 2004; Scherbaum et al 2004). The high rate $(22 \%)$ of younger patients $(<60$ years) who were developing arterial ulcers highlights the demographic changes compared with previous data, and therefore the need for new strategies of prevention.

The long latency period until the patient can be seen in a specialized center for vascular surgery indicates deficiencies in outpatient care and underlines the need to apply the established guidelines (Bendow et al 1999; Spengel 2001; Hopf et al 2006). Other possible risk factors were not evident in our study (Treiman et al 2000; Marston et al 2006; Ince et al 2007). A timely evaluation and treatment can reduce the mortality of this disease (11\%-30\% of patients in 3-5 years in the literature) (getABI Study Group 2002; Cetin and Baumgartner 2002).

Whether the lower mortality of the presented group (11\%) depended on this specialized treatment in a university hospital setting, is speculative and was not further analyzed. The cause of death of admitted patients was of cardiovascular origin.

According to statistical data, 25\% of patients suffering from PAOD stage IV (Fontaine) receive a medication therapy, 25\% undergo a primary amputation, and in 50\% a revascularization is possible (Trans Atlantic Inter-Society Consensus I: TASC I, 2000; Spengel 2001).

According to the TASC II, critical limb ischemia within one year is associated with an amputation rate of $30 \%$ and a mortality of $25 \%$ (Norgren et al 2007). In our 5-year study, the total amputation rate over all patients was $22 \%$. However $37 \%$ of patients were receiving conservative treatment, and only $16 \%$ of the revascularized patients, were affected.

Marston and colleagues (2006) reported an amputation rate of $23 \%$ over a 12 -month period with similar parameters, and in $52 \%$ of these patients complete wound healing was achieved within one year. As a factor of influence the size of the wound was stated; even in our own study, only small wounds healed completely in the conservatively treated group. The effectiveness of prostanoid therapy is a controversial international topic (Spengel 2001; Hopf et al 2006; Minar and Schillinger 2007; Norgren et al 2007). The time needed for healing of the ulcers under study was less than reported in current literature, depending on the criteria for patient inclusion. Ince et al reported an $86 \%$ rate for 52 weeks (Ince et al 2007) and Humphreys and colleagues (2007) reported a rate of $87 \%$ of complete healing of ulcers without PAOD, $68 \%$ with minimal PAOD, and 53\% with severe PAOD. All revascularized ulcers healed within 36 weeks. Chung and colleagues (2006) reported a healing rate of $75 \%$ within 12 months. Treiman and colleagues (2000) showed comparable healing rates of $73 \%$ within 24 weeks and a leg conservation rate of $86 \%$ over 3 years. For all authors the positive outcome of revascularization was the key parameter for success. Our own study however also shows that an extended primary hospital stay for wound treatment, followed by several consequent hospital stays for wound care (including minor and forefoot amputations, debridement), played an important role. Studies on modern treatment of arterial ulcer wounds, which include recommendations of a wound covering, are not available (Bendow et al 1999; Tautenhahn and Piatek 2006; Nelson and Bradley 2007). The principle of wound bed preparation is none the less valid for all chronic wounds. It takes into account the status of the infection, the treatment of gangrene before revascularization of the arterial ulcers, as well as subsequent wound therapy (Bendow et al 1999; Schmidt et al 2000; Schultz et al 2003; Hopf et al 2006; Tautenhahn and Piatek 2006).

Revascularization, diabetes mellitus, and wound therapy prove to be prognostic factors for the pace and efficiency of arterial ulcer wound healing. Further factors and other comorbidities did not appear to have an influence, even in a large patient study group. In agreement with current literature the progress of arteriosclerosis, which is also the underlying cause of the ulcer, contributes to the higher mortality of this group of patients.

\section{References}

Bendow M, Burg G, Camacho Martinez F, et al. 1999. Guidelines for the outpatient treatment of chronic wounds and burns. Berlin Wien: Blackwell.

Cetin C, Baumgartner I. 2004. Die periphere arterielle Verschlusskrankheit. Schweiz Med Forum, 4:216-23.

Chung J, Bartelson BB, Hiatt WR, et al. 2006. Wound healing and functional outcomes after infrainguinal bypass with reversed saphenous vein for critical limb ischemia. J Vasc Surg, 43:1183-90. 
Eckstein HH, Knipfer E. 2007. Current status of vascular surgery. In vascular medicine and general surgery. Chirurg, 78:582-92.

getABI Study Group. 2002. German epidemiological trial on ankle brachial index for elderly patients in family practice to detect peripheral arterial disease, significant marker for high mortality. Vasa, 31:241-8.

Hopf HW, Ueno C, Aslam R, et al. 2006. Guidelines for the treatment of arterial insufficiency ulcers. Wound Rep Reg, 14:693-710.

Humphreys ML, Stewart AH, Gohel MS, et al. 2007. Management of mixed arterial and venouse leg ulcers. Br J Surg, 11:[Epub ahead of print].

Ince P, Game FL, Jeffcoate WJ. 2007a. Rate of healing of neuropathic ulcers of the foot in diabetes and its relationship to ulcer duration and ulcer area. Diabetes Care, 3:660-3.

Knighton DR, Fiegel VD, Austin LL, et al. 1986. Classification and treatment of chronic nonhealing wounds. Succsessful treatment with autologous platelet-derived wound healing factors. Ann Surg, 204:322-9.

Kramer AV, Adrian P, Rudolph S, et al. 1998. Explantationstest mit Haut und Peritoneum der neonatalen Ratte als Voraussagetest zur Verträglichkeit lokaler Antiinfektiva für Wunden und Körperhöhlen. Chirurg, 69:840-5.

Leng GC, Davis M, Baker D. 2000. Bypass surgery for lower limb ischemia. Cochrane Database Syst Rev, 3:CD002000.

Lobmann R. 2005. Pathogenese, Epidemiologie und Klassifikation des diabetischen Fußsyndroms. In: Lobmann R. Eckardt A. (ed). Der diabetische Fuß - Interdisziplinäre Diagnostik und Therapie. Berlin New York: Springer. pp. 1-11.

Marston WA, Davies SW, Armstrong B, et al. 2006. Natural history of limbs with arterial insufficiency and chronic ulceration treated without revascularistion. J Vasc Surg, 44:108-14.

Minar E, Schillinger M. 2007. TASC II - Kommentar aus Sicht des Angiologen. Z Gefässmed, 4:14-17.
Morbach S, Müller E, Reike H, et al. 2004. Diagnostik, Therapie, Verlaufskontrolle und Prävention des diabetischen Fußsyndroms. Diabetes und Stoffwechsel, 13:9-30.

Nelson EA, Bradley MD. 2007. Dressings and topical agents for arterial leg ulcers. The Cochrane Database Syst Rev, 3:CD002000.

Prompers L, Huijbert M, Apelqvist J, et al. 2007. High prevalence of ischaemia, infection and serious comorbidity in patients with diabetic foot disease in Europe. Baseline results from the Eurodiale study. Diabetolgia, 50:18-25.

Schmidt K, Debus ES, Jessberger S, et al. 2000. Bacterial population of chronic crural ulcers: is there a difference between the diabetic, the venous, and the arterial ulcer? Vasa, 29:62-70.

Schultz GS, Sibbald RG, Falanga V, et al. 2003. Wound bed preparation: a systematic approach to wound management. Wound Rep Reg, $11: 1-23$

Shammas NW. 2007. Epidemiology, classification, and modifiable risk factors of peripheral arterial disease. Vasc Health Risk Manag, 3:229-34.

Spengel FA. 2001. Leitlinen zur Diagnostik und Therapie der arteriellen Verschlusskrankheit der Becken-Beinarterien - Deutsche Gesellschaft für Angiologie und Gefäßmedizin. Vasa, 30:3-19.

Tautenhahn J, Piatek S. 2006. Arterielle Ulzerationen. In: Lippert H (ed). Wundatlass. Stuttgart New York: Thieme. pp 213-20.

Trans Atlantic Inter-Society Consensus (TASC I). 2000. Management of peripheral Arterial Disease. Eur J Vasc Endovasc Surg, 19:1-250.

Treiman GS, Oderich GS, Ashrafi A, et al. 2000. Management of ischemic heel ulceration and gangrene: An evaluation of factors associated with successful healing. J Vasc Surg, 31:1110-18.

Vollmar J. 1996. Rekonstruktive Chirurgie der Arterien. Stuttgart New York: Thieme. 
